\title{
Avaliação da remoção da camada primer num processo de pintura automotiva, efeitos econômicos e impactos ambientais
}

Evaluation of the removal of primer coating in an automotive painting process, economical effects and environmental impact

\author{
Carla Dalmolin', Felipe Freire Gonçalves², Wagner Mauricio Pachekoski ${ }^{2}$ \\ 'Departamento de Química, Universidade do Estado de Santa Catarina \\ ${ }^{2}$ Faculdade de Tecnologia SENAI Cimatec
}

\begin{abstract}
Resumo
A indústria automotiva mundial enfrenta fortes pressões no sentido de reduzir os impactos ambientais causados pelo seu processo produtivo. Em paralelo a isso, a elevada competitividade do mercado de automóveis faz com que a busca pela redução de custos e aumento da produtividade sejam constantes neste segmento da indústria. Diante da questão sobre como reduzir os impactos ambientais e aumentar a produtividade de processos de pintura automotiva propôs-se investigar a possibilidade de remoção de uma camada de tinta de uma configuração de pintura comumente adotada na indústria automotiva, estudando os efeitos desta ação nas propriedades do revestimento, através de ensaios em laboratório e testes práticos em fábrica. Os testes em laboratório compreenderam a análise das propriedades das chapas revestidas com a configuração proposta em comparação com as propriedades da pintura original, enquanto os testes em fábrica envolveram avaliações de chapas e protótipos para ensaios dentro processo produtivo. A grande maioria dos resultados obtidos permitiu concluir que o sistema de pintura proposto funciona. A utilização da configuração proposta possibilitaria o aumento de produtividade e ganhos ambientais, por exemplo, através da redução do consumo de produtos químicos e das emissões atmosféricas.
\end{abstract}

Palavras-chave: pintura automotiva, economia ambiental, sustentabilidade

\begin{abstract}
Automotive industry worldwide faces strong pressures towards the reduction of environmental impacts caused by the productive process. At the same time, the highly competitive car market causes an increasingly constant search for cost reduction and productivity rising in this industrial segment. Facing this need for reduction on the environmental impact associated with the increase of productivity in the automotive painting processes, this study proposes the investigation of the possibility to remove the paint layer known as primer, evaluating the effects on coating properties through laboratory analysis and tests inside the production line. The laboratory tests involved the comparison between the proposed paint structure and original paint structure properties, while tests in the production line involved the evaluation of panels and prototypes. Almost all results showed that the paint system proposed works properly. The adoption of proposed paint structure would allow environmental performance gains and productivity increasing by reducing chemicals usage and atmospheric emissions.
\end{abstract}

Keywords: automotive painting, environmental economy, sustainability 


\section{INTRODUÇÃO}

As indústrias do setor automotivo fazem parte de um negócio cujo mercado caracteriza-se pela alta competitividade. No início da segunda década do século XXI, o número de montadoras que injeta novos produtos e tecnologias com o objetivo de atrair é bem maior do que nas décadas de 60 e 70 do século passado, no qual as principais montadoras se instalaram e desenvolveram a produção de automóveis no país. O crescimento vertiginoso do consumo de produtos industrializados, inclusive o de automóveis, levou a comunidade internacional a perceber a facilidade com que poderiam ser atingidos os limites do planeta. Observaram-se, a partir disso, novas direções da jurisprudência ambiental, com o surgimento de princípios ambientais e de um maior rigor das leis e resoluções relacionadas ao meio ambiente.

Assim, em paralelo ao cenário de elevada competitividade (no contexto dos sistemas produtivos de um modo geral), cresce a importância do conceito de produção mais limpa e aumento da ecoeficiência, não puramente por atendimento à requerimentos legais e pressões da sociedade, mas também por oportunidade de retorno financeiro. As tendências ambientais apontam para a necessidade do setor produtivo se voltar para soluções preventivas, e não mais corretivas, a partir da minimização de impactos ambientais no próprio processo de fabricação. Por exemplo, pela redução da geração de resíduos e pela otimização do uso de insumos necessários.

A busca pela Produção mais Limpa na indústria de um modo geral vem crescendo, seja pelo aumento do rigor na legislação ambiental, e consequentemente da necessidade de cumprimento dos requerimentos legais, seja por uma necessidade de se obter e manter uma certificação do Sistema de Gestão Ambiental (ISO 14001), ou ainda por oportunidades de redução de custos. De uma forma geral, o conceito de Produção Mais Limpa pode ser definido como um conjunto de estratégias, práticas e condutas que evitam ou reduzem a geração de resíduos por meio de ações preventivas, ou seja, através do aumento da eficiência da utilização de recursos e da criação de alternativas para que estes recursos sejam reutilizados ou reciclados (CETESB, 2006).

Os principais impactos ambientais associados à produção de um veículo estão relacionados com o processo de proteção e acabamento das estruturas metálicas, que correspondem a mais de $75 \%$ do produto completo. O processo de pintura de superfícies metálicas é complexo e, em linhas gerais, a tecnologia mais utilizada nos dias atuais pode ser dividida nas seguintes etapas: preparação da superfície, cobertura anti-corrosiva, selagem da carroceria, aplicação das tintas primária e de acabamento. Nos EUA, já há uma tendência de queda e estabilização nas quantidades de compostos tóxicos emitidos pela indústria automotiva (Kiperstok, 2000). Esta redução pode ser creditada a diversas medidas tomadas especificamente para o setor de pintura e acabamento, como o uso de técnicas de pintura mais eficientes e tintas com menor conteúdo de solventes, inclusive tintas a base de água; a otimização das sequências de pintura, para minimizar a necessidade de limpeza e carregamento de tinta dos equipamentos na troca de cores, reduzindo o uso de solventes, tintas e consequentemente as emissões de compostos orgânicos voláteis (VOC) e geração de borra de tinta; um programa de redução de compostos tóxicos no revestimento de superfícies, incluindo VOC, chumbo e cromo hexavalente.

Desta maneira, as etapas finais do processo de pintura automotiva foram o foco deste trabalho. As tintas primárias (primers) são usadas para recobrimento do corpo metálico antes da aplicação da tinta de acabamento. Sua principal função é corrigir pequenos defeitos de superfície e melhorar a aderência do acabamento. A proposta deste trabalho é a eliminação do primer em regiões de difícil acesso e pouca visibilidade, garantido a manutenção das principais características de qualidade, com o foco na possibilidade de redução de impacto ambiental e aumento de produtividade do processo produtivo.

\section{METODOLOGIA}

A indústria automotiva enfrenta pressões crescentes na dimensão ambiental. Essas pressões aparecem na forma de rígidas e complexas regulamentações, além de crescentes demandas das partes interessadas na melhoria do desempenho ambiental das organizações. A forma como uma planta responde a estas questões tem implicações significativas nos custos e na qualidade das operações de uma empresa. Porém, o cumprimento das exigências ambientais vem deixando de ser entendida como um custo adicional de produção, com a instalação de tecnologias fim de tubo, e passando para uma avaliação mais detalhada dos processos fundamentais de um sistema de produção, sugerindo mudanças de tecnologia e materiais que 
resultassem na prevenção da poluição na fonte (Mello e Nascimento, 2002). Essa mudança de entendimento justifica-se, sobretudo, pelo aumento dos custos associados aos modos de atendimento tradicionais, ou fim de tubo, e aos avanços em tecnologias de materiais e processos.

Diferentes instrumentos podem ser utilizados para o desenvolvimento da proposta de ecoeficiência. Dentre eles pode-se citar o Sistema de Gestão Ambiental (SGA), estruturado nas normas ISO série 14.000 , a abordagem da produção mais limpa e, mais recentemente, a análise do ciclo de vida (Potrich et al., 2007). O maior impacto durante o ciclo de vida de um automóvel é gerado durante seu uso, porém os impactos ambientais associados ao processo de fabricação também são de grande significância. A principal fonte de emissões atmosféricas e destinação de produtos perigosos numa fábrica de automóveis é o setor de pintura. Estima-se que mais de $80 \%$ das preocupações ambientais nestas unidades são oriundas dos processos de pintura e suas operações relacionadas (Geffen e Rothenberg, 2000).

O processo de pintura é complexo e apresenta intenso consumo de energia e água. A pintura é também a principal fonte de emissão de componentes orgânicos voláteis (COV) e outros poluentes perigosos, por exemplo, na forma de resíduos sólidos. Este processo é também o mais dispendioso de uma indústria automotiva devido aos altos custos dos equipamentos e material usados na pintura, e ainda aos custos destinados ao controle ambiental, sobretudo ao controle de emissões atmosféricas (Geffen e Rothenberg, 2000). Uma das direções mais efetivas para a redução das emissões e geração de resíduos perigosos pela pintura é a redução do uso de substâncias químicas através da substituição de materiais e implantação de novas tecnologias. Tintas base água e tintas em pó, por exemplo, contém menores proporções de compostos orgânicos voláteis e outras substâncias tóxicas, e sua utilização reduziria o nível de poluentes para o controle ou tratamento. No entanto, a importância do acabamento final nas vendas associada aos altos custos e complexidades inerentes ao processo de pintura mantém os fabricantes relutantes em adotar essas novas tecnologias sem extensiva realização de testes. Novos materiais e tecnologias precisam atender ou superar rigorosos requerimentos da qualidade antes de serem considerados para aplicação numa unidade de produção (Geffen e Rothenberg, 2000). A demora na aprovação e implantação de novas tecnologias e materiais de melhor desempenho ambiental é, portanto, um dos motivos pelos quais a otimização do consumo dos materiais usados no processo atual é uma importante ação no sentido da redução dos impactos ambientais de um sistema de pintura.

Segundo Santos et al. (2007), avaliações sobre a influência e a percepção sobre a sustentabilidade ambiental foram realizadas em empresas do setor automotivo da Região Metropolitana de Curitiba. Identificou-se que a adoção de tecnologias voltadas para a minimização dos impactos sobre o meio ambiente e a implantação do Sistema de Gestão Ambiental (SGA) nas organizações contribuem positivamente para a sustentabilidade ambiental da região. Segundo a pesquisa, o bom desempenho ambiental manifestou-se através da gestão adequada de resíduos sólidos, emissões atmosféricas, efluentes líquidos e uso de recursos naturais, que ocorrem dentro dos padrões exigidos pelos órgãos fiscalizadores em função, sobretudo, do descarte adequado de resíduos e da utilização de sistemas de controle e tratamento das emissões atmosféricas e efluentes líquidos. A pesquisa apontou ainda que o desempenho é explicado inicialmente pela preocupação no atendimento dos requisitos da legislação, justificada por $80 \%$ das empresas como a principal razão para investir no SGA.

Atualmente são encontradas as mais variadas ideias voltadas para a redução dos impactos e aumento do desempenho ambiental na indústria automotiva. O reaproveitamento de rejeitos das cabines de pintura para geração de eletricidade e produção de vapor é uma delas. A possibilidade de cogeração contribui com a racionalidade energética, uma vez que possibilita um melhor aproveitamento dos combustíveis, apresentando menor consumo total quando comparada à geração individual de calor e energia elétrica (Guerini, 2005). A redução do consumo de tintas foi a idéia voltada para a minimização de impactos ambientais, e consequente aumento do desempenho ambiental, da organização de referência deste trabalho.

A importância da busca pela Produção Mais Limpa $(\mathrm{P}+\mathrm{L})$, ou seja, da adoção de medidas preventivas com o foco na minimização ou eliminação da geração de resíduos é indiscutível diante do que foi brevemente discutido. Está claro que as empresas precisam se dedicar na redução dos impactos ambientais não somente pela obrigação que têm junto aos órgãos ambientais, mas também pela possibilidade de redução de custos e aumento da aceitação dos seus produtos pelos clientes cada vez mais preocupados com a preservação do meio 


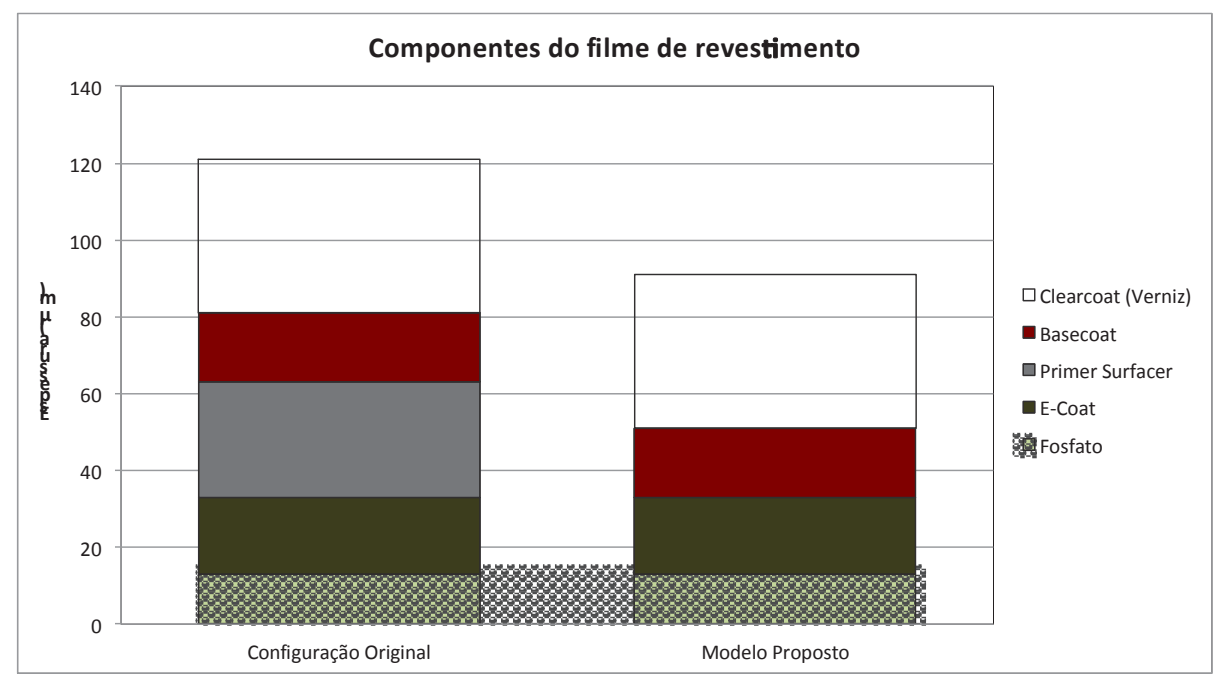

Figura 1: Comparações de espessura e camadas de pintura na configuração original (atualmente utilizada na indústria automotiva) e na configuração proposta com a remoção do primer.

ambiente numa escala global.

O processo de pintura automotiva tem duas funções essenciais. A primeira delas está associada a aparência do produto. A segunda é proteger a estrutura metálica do carro contra corrosão. Juntamente com o design do carro, a pintura está, inevitavelmente, presente no primeiro contato do cliente com o produto. A partir da década de 1970 os clientes começaram a se tornar cada vez mais exigentes quanto à aparência dos seus veículos, e então a indústria de pintura automotiva teve que se adaptar a uma nova demanda. Além disso, este segmento precisou se adaptar também às exigências dos órgãos ambientais. As primeiras tintas para pintura automotiva e seus processos de aplicação ineficientes foram responsáveis pelo lançamento de milhares de toneladas de poluentes na atmosfera, e face às novas tendências ambientais isso não poderia mais ser permitido. Mudanças drásticas e fundamentais ocorreram ao longo dos anos na química das tintas e nas técnicas de aplicação para atendimento à legislação ambiental e às demandas dos clientes (Pfanstiehl, 1998).

A evolução dos sistemas de pintura automotiva levou a uma quase padronização deste processo (Fazenda, 2005). Os componentes aplicados acima do substrato metálico são, na grande maioria das indústrias automotivas:

- Camada de Fosfato

- Camada de E-Coat

- Camada de Primer Surfacer

- Camada de Basecoat

- Camada de Clearcoat
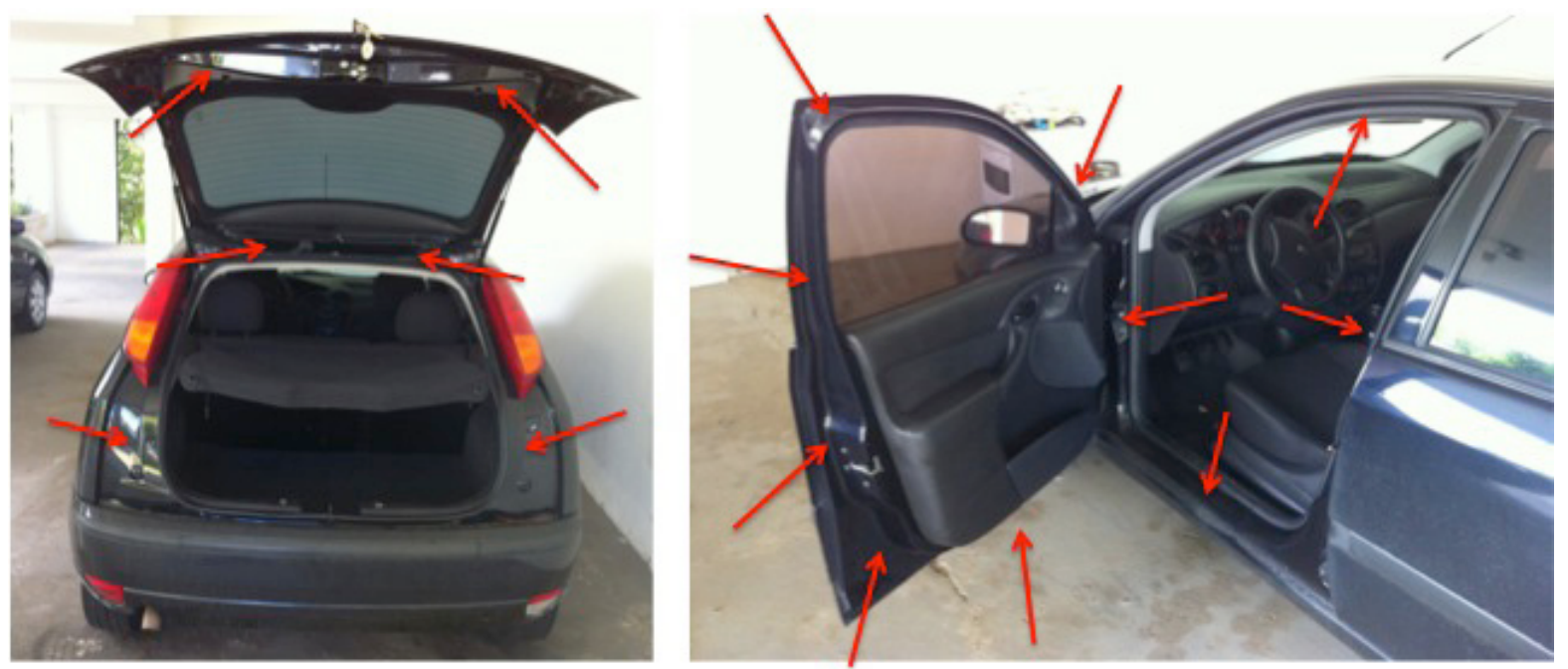

Figura 2: Regiões de pintura escolhidas para o estudo da configuração proposta, sem a camada de primer nos internos 
As camadas Fosfato e E-Coat são responsável pela proteção á corrosão do aço comum, material mais usado na produção dos corpos metálicos, ou carrocerias. As camadas Basecoat e Clearcoat são responsáveis pela cor e aparência da pintura, enquanto a camada Primer Surfacer promove a correção da superfície e melhora a interação entre as camadas de proteção (e-coat) e de finalização (basecoat). Pensando na redução de consumo de tintas e/ou solventes, a eliminação da camada primária denominada Primer Surfacer, ou apenas primer, pode ser visualizada pelo esquema da Figura 1.

Num processo de pintura podem ser identificadas várias características de qualidade importantes para o cliente. Com base em reclamações de campo, reclamação de clientes internos e análises de benchmarking é possível realizar um levantamento das principais características necessárias para o atendimento das expectativas de qualidade dos clientes (Pierozan, 2001). A compreensão das demandas da qualidade é de fundamental importância para o entendimento dos resultados encontrados nos trabalhos experimentais. Ou seja, deve-se considerar que, para efeitos visuais, um esquema de pintura com a remoção da camada primer seria viável para a indústria automotiva apenas nas partes do veículo de difícil acesso, conforme ilustradas na Figura 2.

De acordo com as expectativas relacionadas à aparência e às propriedades de resistência da pintura, e considerando limitações associadas aos materiais e aos equipamentos de aplicação, bem como dos recursos financeiros direcionados para melhorias da qualidade, as unidades de pintura automotiva definem os padrões para seus revestimentos. Com base nestes padrões originam-se as especificações, que são os requisitos mínimos a serem atendidos pela pintura e que não são necessariamente idênticas em todas as fábricas de veículos. Os requisitos gerais e os métodos de avaliação estão apresentados a diante nos seguintes grupos:

- Cor e aparência;

- Resistência ao intemperismo;

- Proteção contra corrosão;

- Propriedades mecânicas.

Para os ensaios laboratoriais foram utilizados como corpos de provas chapas de aço (300 x $100 \mathrm{~mm}$ ), fosfatizadas e revestidas pela camada anti-corrosiva (e-coat). As chapas foram pintadas de acordo com o processo original de pintura e com a retirada da camada primer, envolvendo cinco cores comuns na indústria automotiva (neste estudo denominadas branco, prata, vermelho, azul e preto). Posteriormente, foram realizadas análises para determinar as características de qualidade, listadas abaixo:

- Análise de cobertura e cor;

- Análise Distinção de Imagem (DOI);

- Aderência entre camadas;

- Imersão em água;

- Resistência à corrosão por névoa salina e ciclo ambiental;

- Resistência à batida de pedras.

Apesar de terem significados distintos, os conceitos de produtividade e eficiência estão intimamente ligados e proporcionam uma gama elevada de definições, que podem ser antagônicas a depender do ponto de vista ou interesse de quem define. $\mathrm{O}$ conceito de produtividade mostra relações existentes entre entradas e saídas de um sistema fechado (Nigro, 2005). No caso deste trabalho, o sistema fechado deve ser entendido como o processo de pintura automotiva. Deve-se considerar ainda a produtividade como o aumento da capacidade produtiva, ou o aumento da quantidade produzida com a mesma disponibilidade de recursos do ponto de vista da organização. Partindo-se do conceito de uma organização como um sistema com entradas e saídas, deve-se compreender que a eficiência deste sistema está associada à melhor utilização dos recursos (entradas) disponíveis. Ao considerar a possibilidade de eliminação de uma camada de tinta de um sistema de pintura tradicional, levando em consideração a manutenção da qualidade e das propriedades de proteção e acabamento do produto, o trabalho propõe um caso claro de aumento de produtividade. Em outras palavras, produção da mesma quantidade de veículos, com a utilização de um volume menor de recurso, no caso específico, tinta, mão-de-obra, solventes, ferramentas, dentre outros.

A etapa de avaliação dos indicadores e estimativas de ganhos baseou-se na obtenção de dados reais na linha de produção e em estudos de estimativa. Os dados reais referiram-se à medição do volume de primer, base e verniz aplicados nos protótipos, onde foi avaliada a redução do consumo em comparação com o processo original. Com base nessas medições, foram estimados os ganhos associados principalmente às reduções do consumo de solventes e emissões atmosféricas, adotando-se como metodologia a análise de 
balanço de massa e análise de inventário. Foram avaliadas ainda as possibilidades de redução de mão-de-obra, redução do consumo de material industrial e melhoria ergonômica, utilizando-se de depoimentos de operadores durante a pintura dos protótipos e estimativas baseadas no controle de consumo de materiais (planilhas de controle de custos).

\section{RESULTADOS E DISCUSSÃO}

A utilização do primer colorido antes da tinta base tem como finalidade aumentar o poder de cobertura do sistema, ou seja, de contribuir com a formação do revestimento sem falhas entre a superfície visível e o substrato ou camadas intermediárias do revestimento. Intuitivamente fica claro imaginar que para "esconder" o e-coat verde musgo com basecoat vermelho, por exemplo, precisa-se de mais tinta do que para "esconder" um primer vermelho com o mesmo basecoat vermelho. $\mathrm{Da}$ mesma maneira, precisa-se de mais tinta branca para recobrir totalmente o e-coat verde musgo do que para recobrir um primer branco.

A Figura 3 representa o caso extremo do teste de cobertura e cor, ou seja, a cor branca branca aplicada sobre o e-coat verde-musgo. Nos gráficos representados na Figura 4 são exibidos os resultados das análises de cobertura seca para a cor branca com e sem a aplicação do primer. Para a correta interpretação dos resultados deve-se compreender que um menor valor de DEcmc significa menor variação entre a cor analisada e a cor padrão, cujos parâmetros são definidos e fixados ainda na fase de projeto. Isso significa dizer que quanto menor o DEcmc, menor a diferença entre a cor analisada e a cor padrão, ou maior a semelhança desta cor com a referência.
Deve-se saber adicionalmente que a redução da variação de cor está relacionada com a aplicação de tinta numa faixa adequada de espessura. A camada de tinta deve respeitar valores mínimos e máximos de referência. Enquanto camadas finas correspondem a um recobrimento pobre, camadas muito espessas podem gerar discrepância contra o padrão pelo excesso de pigmentos transferidos para a carroceria, podendo deixar a pintura azulada, avermelhada etc., por exemplo. Vale ressaltar que a medição de cor foi feita em painéis revestidos até o nível do verniz, ou seja, em chapas pintadas com e-coat, primer, base e verniz (painéis com a configuração original) e com e-coat, base e verniz (painéis com a configuração proposta).

Analisando as Figuras 4 a e $b$ percebe-se que a pintura da base sobre o e-coat, ou seja, sem a utilização do primer entre essas duas camadas, faz com que a estabilização da diferença de cor com o padrão ocorra em níveis mais altos de camada em comparação com o filme original. Conforme explicado anteriormente, neste caso a cobertura seria mais difícil de se atingir se comparado com a configuração original. Se o mesmo comportamento fosse observado em todas as medições, isso indicaria um aumento de consumo de basecoat e o aparecimento de problemas de qualidade, como fervuras e craqueamento, mas não foi o caso. Para a cor em questão, que possui o pior poder de cobertura entre as cores avaliadas, este comportamento não representaria um problema, pois a camada deste material aplicada nos painéis internos é acima da zona de estabilização encontrada.

Conforme discutido anteriormente, além de contribuir com o nivelamento do filme de tinta e facilitar a cobertura do basecoat, o primer promove a aderência entre as camadas de e-coat e basecoat. Sabendo-se que quanto maior o poder de aderência entre camadas, maior é a firmeza entre

\section{Sem Primer}

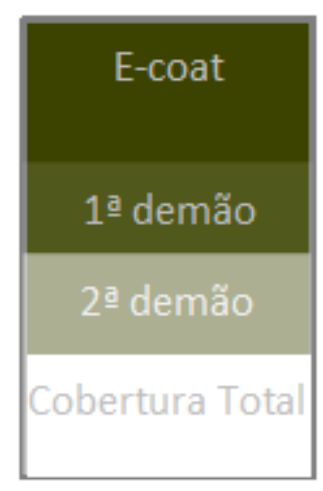

\section{Com Primer}

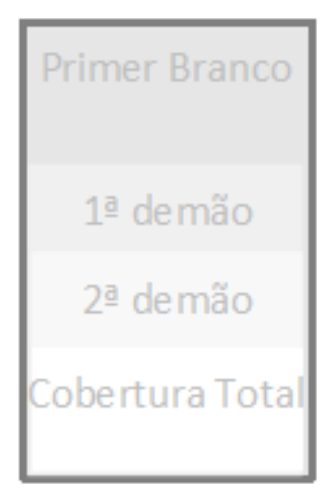

Figura 3: Exemplo da dificuldade de cobertura total da camada de e-coat (verde-musgo) por uma tinta na cor branca, nos processos onde foi suprimida a camada primer (esquerda) e no processo original (direita). 
(a)

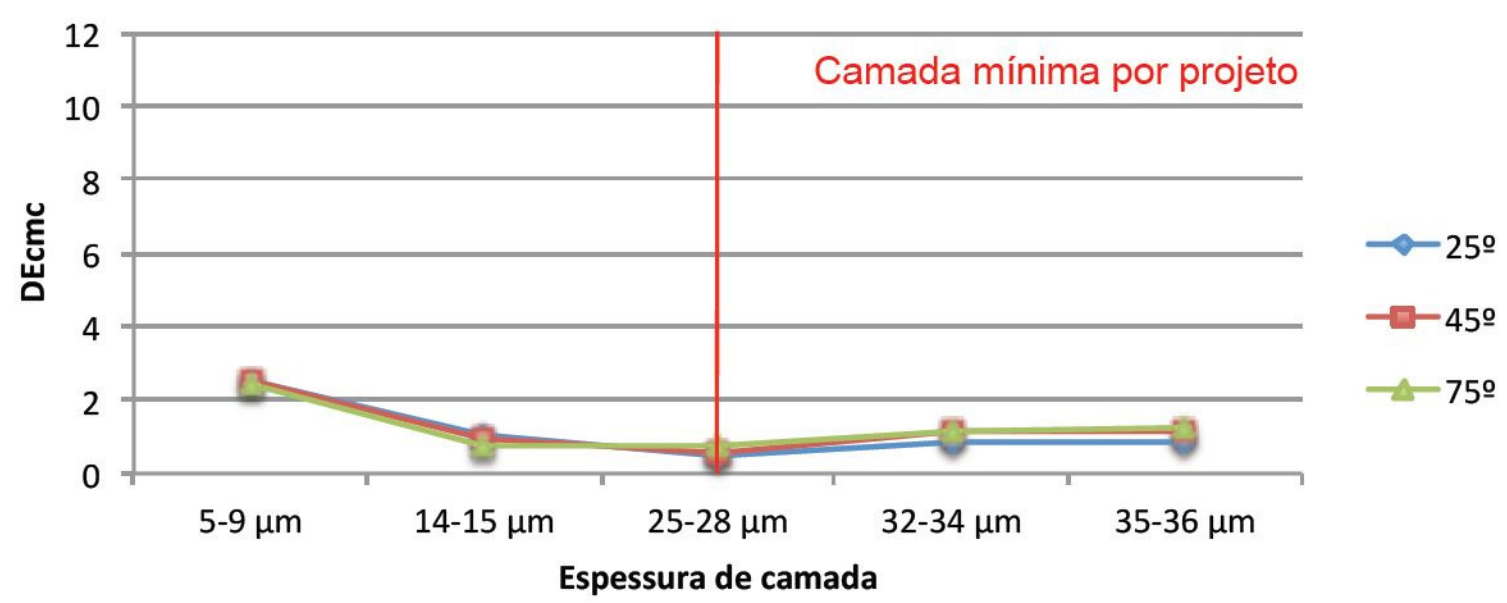

(b)

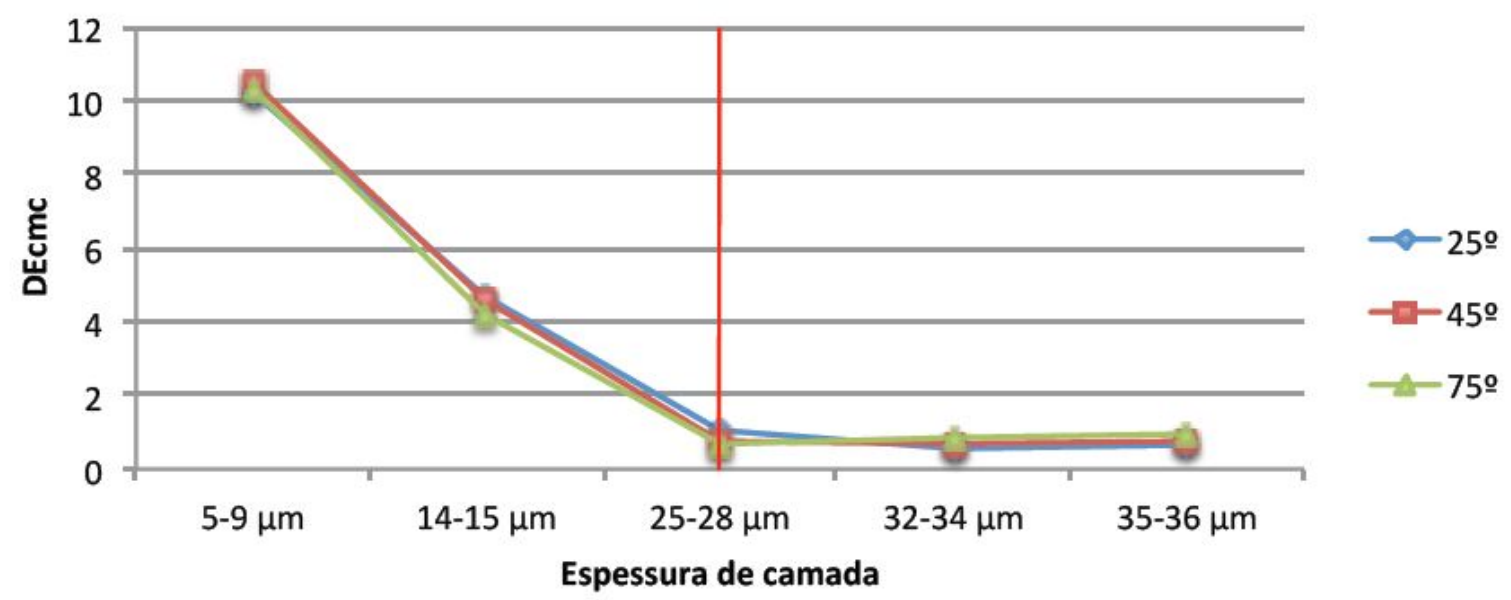

Figura 4: Análise de cobertura e cor obtida em três ângulos diferentes dos corpos de prova pintados na cor branca, (a) com a camada primer e (b) sem a camada primer.

as suas ligações e, portanto, menor é a possibilidade de desplacamentos de tinta, identificou-se como indispensável a verificação da aderência entre camadas no filme proposto, uma vez que a tinta base passaria a ser aplicada diretamente sobre o e-coat, e não mais sobre o primer, ou seja, sobre um material diferente daquele adotado na configuração original.

A Figura 5 mostra os resultados dos ensaios de aderência entre camadas, e pode-se afirmar que as diferenças entre o filme proposto em comparação com o filme original não foram significativas. Isso indica que a influência do primer para a aderência entre camadas, neste caso, não foi tão significativa quanto a influência do basecoat propriamente dito. E possível concluir que o e-coat, que é um primer em sua essência, também possui propriedades de aderência com o basecoat ao passar pela estufa.

A Tabela 1 mostra os principais resultados dos demais testes de qualidade para os corpos de prova pintados nas diferentes cores estudadas pelo processo sem a utilização da camada primer. Os níveis de distinção de imagem ficaram acima do limite mínimo aceitável, assim como os testes de aderência, imersão em água e corrosão mostraram que a pintura dos substratos é resistente a estas condições.

Entretanto, pela análise de resistência a batida de pedras foi possível notar que, nas chapas pintadas sem o primer, a profundidade dos desplacamentos atingiu o substrato metálico, o que não deve ocorrer em filmes pintados com a configuração original. Este resultado é coerente com o processo de pintura utilizado, uma vez que os filmes produzidos apresentam uma redução de cerca de $25 \%$ da espessura de camada quando comparados com a espessura do filme original. Através desta análise é possível concluir 
$\operatorname{Cor} \# 1$

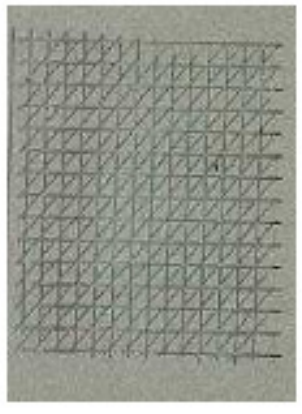

Cor \#5

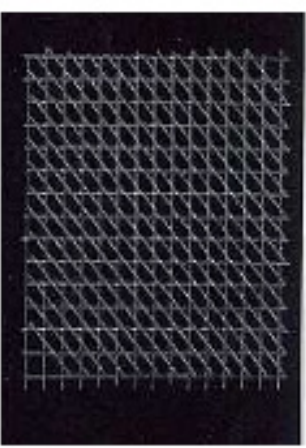

$\operatorname{Cor} \# 2$

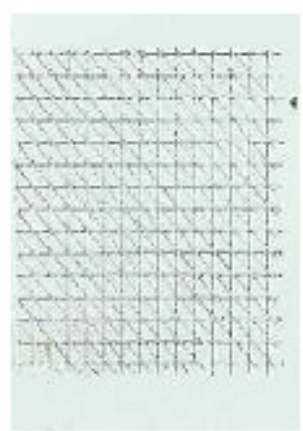

Cor $\# 6$

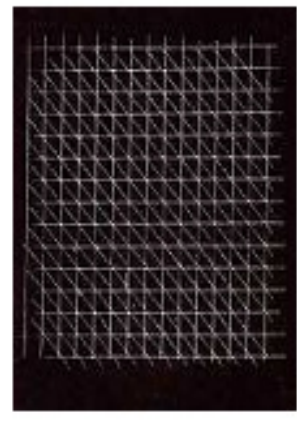

Cor \#3

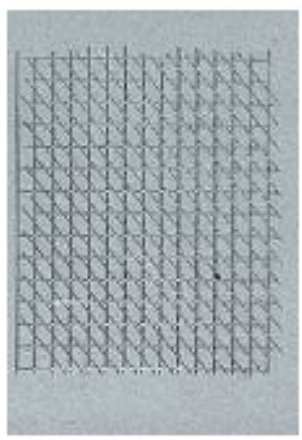

Cor \#7

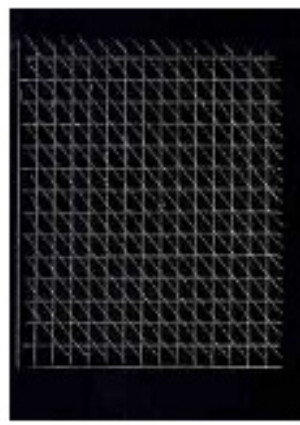

Cor \#4

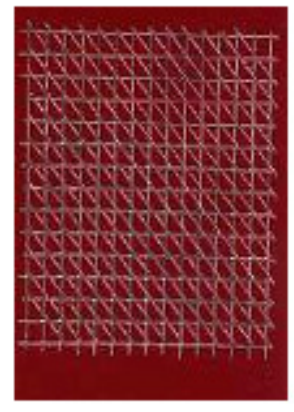

Cor \#8

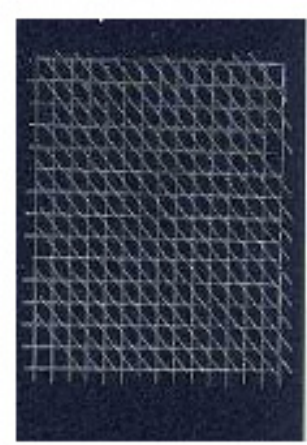

Figura 5: Resultado dos testes de aderência entre camadas.

Tabela 1: Resultados dos testes de qualidade dos corpos de provas pintados pelo processo sem camada primer.

\begin{tabular}{|l|c|c|c|c|c|}
\hline \multicolumn{1}{|c|}{$\begin{array}{c}\text { Teste de } \\
\text { Qualidade }\end{array}$} & Branco & Prata & Vermelho & Azul & Preto \\
\cline { 2 - 6 } $\begin{array}{l}\text { Distinção } \\
\text { de imagem } \\
\text { (mínimo } \\
\text { aceitável:70) }\end{array}$ & 86,2 & 82,7 & 82,8 & 85,7 & 86,4 \\
\hline Aderência & $\begin{array}{c}\text { Não houve } \\
\text { desplacamento }\end{array}$ & $\begin{array}{c}\text { Não houve } \\
\text { desplacamento }\end{array}$ & $\begin{array}{c}\text { Não houve } \\
\text { desplacamento }\end{array}$ & $\begin{array}{c}\text { Não houve } \\
\text { desplacamento }\end{array}$ & $\begin{array}{c}\text { Não houve } \\
\text { desplacamento }\end{array}$ \\
\hline $\begin{array}{l}\text { Imersão em } \\
\text { água }\end{array}$ & $\begin{array}{c}\text { Sem formação } \\
\text { de bolhas }\end{array}$ & $\begin{array}{c}\text { Sem formação } \\
\text { de bolhas }\end{array}$ & $\begin{array}{c}\text { Sem formação } \\
\text { de bolhas }\end{array}$ & $\begin{array}{c}\text { Sem formação } \\
\text { de bolhas }\end{array}$ & $\begin{array}{c}\text { Sem formação } \\
\text { de bolhas }\end{array}$ \\
\hline $\begin{array}{l}\text { Corrosão em } \\
\text { névoa salina } \\
\text { (75 h) }\end{array}$ & Resistente & Resistente & Resistente & Resistente & Resistente \\
\hline $\begin{array}{l}\text { Resistência } \\
\text { a batida de } \\
\text { pedras }\end{array}$ & $\begin{array}{c}\text { Desplacamento } \\
\text { até o substrato } \\
\text { metálico }\end{array}$ & $\begin{array}{c}\text { Desplacamento } \\
\text { até o substrato } \\
\text { metálico }\end{array}$ & $\begin{array}{c}\text { Desplacamento } \\
\text { até o substrato } \\
\text { metálico }\end{array}$ & $\begin{array}{c}\text { Desplacamento } \\
\text { até o substrato } \\
\text { metálico }\end{array}$ & $\begin{array}{c}\text { Desplacamento } \\
\text { até o substrato } \\
\text { metálico }\end{array}$ \\
\hline
\end{tabular}




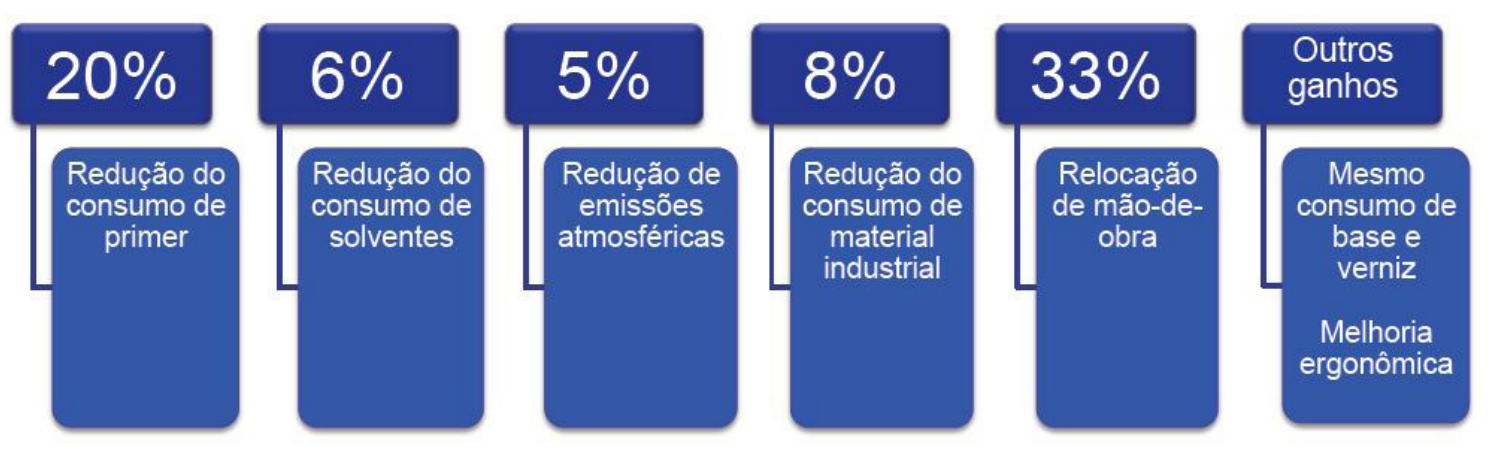

Figura 6: Estimativas dos impactos associados com a substituição do processo de pintura automotiva original pela remoção da camada primer nas regiões internas de carrocerias de veículos.

que a remoção do primer em áreas que sofrem constantes impactos de pedras ou outros objetos poderia desencadear um processo de corrosão causado pela exposição do substrato metálico ao ar livre. No entanto, levando-se em consideração que a proposta de remoção do primer do filme de tinta é feita somente para áreas internas das carrocerias, que estão constantemente protegidas contra impactos de objetos, isto não representaria um problema.

No ensaio do ciclo ambiental constatou-se ausência de formação de bolhas e craqueamento de tinta (rachaduras), mostrando resultado satisfatório para todas as cores testadas. Assim como em outros testes, não foi evidenciada diferença significativa entre a resposta dos painéis revestidos sem primer em comparação com os painéis revestidos com o filme original, contendo primer. Entretanto, os testes foram realizados em corpos de prova planos, não levando em consideração os diferentes formatos das peças, que podem ocasionar corrosão por frestas, por exemplo.

Além das análises técnicas sobre o comportamento de algumas propriedades do filme de tinta proposto, foi possível realizar o levantamento de algumas informações durante a etapa dos ensaios no processo de referência e, com isso, fazer estimativas quantitativas de ganhos decorrentes da implementação do processo, esquematizadas na Figura 6. A redução em $20 \%$ no consumo de tintas e solventes é devida basicamente à supressão da camada primer, uma vez que não há variação no consumo de tintas relacionadas com as camadas de acabamento. Esta estimativa foi realizada com base no conhecimento da área pintada e da vazão das pistolas de aplicação. A previsão foi confirmada através da pintura de protótipos de ensaio na etapa dos testes práticos no processo real e da medição da variação de nível dos containers de tinta. Ainda, a redução do consumo de primer implicaria na redução do consumo de solventes, tanto de forma direta quanto indireta. A redução ocorreria diretamente com a redução do consumo de solventes de diluição e indiretamente através da redução do consumo de solvente utilizado na limpeza das ferramentas de aplicação. A estimativa de redução foi da ordem de $6 \%$.

Em termos de mão-de-obra, o processo proposto possibilitaria a relocação de $33 \%$ do pessoal dedicado à aplicação de primer em áreas internas. Outras reduções diretas de custo foram identificadas, causados sobretudo pela redução de consumo de material industrial e pela manutenção de ferramentas de aplicação, correspondendo a $8 \%$ do custo anual associado ao processo de pintura original. Durante os testes em fábrica não foram observadas reduções de retrabalho, aumento da taxa de entrega pela redução da necessidade de parada de linha. Percebeu-se, também, uma melhoria ergonômica no processo proposto.

\section{CONCLUSÃO}

Os resultados obtidos através dos ensaios em laboratório e das atividades práticas no processo permitiram concluir que a proposta de utilização de uma configuração de pintura de menor impacto ambiental, sem a utilização de uma das camadas de tinta usadas na configuração tradicional de pintura, em áreas específicas de regiões internas dos veículos, seria tecnicamente viável de acordo com todas as avaliações, com exceção do teste de resistência ao salt spray, do qual não foram obtidos resultados conclusivos. Em nenhum outro ensaio de laboratório e em nenhuma atividade prática no 
processo de pintura foram identificados impeditivos técnicos para a implementação da configuração de pintura proposta, ou seja, é possível afirmar sem dúvidas que a pintura proposta atenderia perfeitamente aos requisitos técnicos e aos critérios de qualidade exigidos.

Concluiu-se também que seria possível obter ganhos associados à redução de impactos ambientais e, portanto, relacionados ao aumento do desempenho ambiental da organização, sem a necessidade de investimentos, somente com a quebra de paradigmas. Estes ganhos foram quantificados principalmente na forma de redução de emissões atmosféricas e redução do consumo de produtos químicos, como tintas e solventes.

\section{REFERÊNCIAS}

CETESB - Companhia de Tecnologia de Saneamento Ambiental. Guia técnico ambiental tintas e vernizes - série P+L. São Paulo, 2006. 70 p.

FAZENDA, Jorge M. R. Tintas e Vernizes. 3. ed. São Paulo: Edgar Blücher, 2005. 1044 p.

GEFFEN, C. A., ROTHENBERG, S. Suppliers and Environmental Innovation: The Automotive Paint Process. International Journal of Operations and Production Management. Volume 20, n. 20, 2000. p. 166-186.

GUERINI, E. H., Utilização do rejeito das cabines de pintura para gerar eletricidade e produzir vapor. Trabalho de curso (Mestrado Profissionalizante em Engenharia Automotiva) - Escola Politécnica da Universidade de São Paulo. São Paulo, 2005. 131 p.

KIPERSTOK, A. Tendências ambientais do setor automotivo: prevenção da poluição e oportunidades de negócio. Revista NEXOS. Mestrado em Economia. UFBA. Salvador, 2000.

MELLO, M. C. A., NASCIMENTO, L. F. Produção mais limpa: um impulso para a inovação e a obtenção de vantagens competitivas. XXII Encontro de Engenharia de Produção. ABEPRO. Curitiba, 2002. 8 p.

NIGRO, I. S. C. Refletindo sobre produtividade. XII SIMPEP - Simpósio de Engenharia de Produção. Bauru, 2005.
New York: HPBooks, 1998. 176 p.

PIEROZAN, L. Estabilização de processos: um estudo de caso no setor de pintura automotiva. Mestrado Profissionalizante em Engenharia. UFRGS. Porto Alegre, 2001.

POTRICH, A. L., TEIXEIRA, C. E., FINOTTI, A. R. Avaliação de impactos ambientais como ferramenta de gestão ambiental aplicada aos resíduos sólidos do setor de pintura de uma indústria automotiva. Estudos Tecnológicos em Engenharia - vol. 3, no 3. ISSN 1808-7310. 2007, p. 162-175.

SANTOS, S. E., ANDREOLI, C. V., SILVA, C. L. Práticas ambientais das empresas do setor automotivo da região metropolitana de Curitiba. II Seminário sobre sustentabilidade. Mestrado em Organizações e Desenvolvimento. Centro Universitário Franciscano - FAE. Curitiba, 2007. 15 p.

PFANSTIEHL, J. Automotive Paint Handbook. 